\title{
Information system "BW_Abfluss": regionalisation of flood, mean and low flow parameters
}

\author{
A. S. Blatter, J. Liebert, P. A. Preuss, J. Szabadics, and J. Ihringer \\ Institute of Water and River Basin Management (IWG) (http://www.iwg.uni-karlsruhe.de), Universität Karlsruhe (TH), \\ Germany
}

Received: 16 January 2007 - Revised: 11 April 2007 - Accepted: 15 May 2007 - Published: 1 June 2007

\begin{abstract}
On behalf of and in close collaboration with the institution of environment, measurements and conservation of the federal state of BadenWürttemberg (Landesanstalt für Umwelt, Messungen und Naturschutz Baden-Württemberg/LUBW/ see http://www.lubw.baden-wuerttemberg.de/) an innovative regionnalisation concept has been developed. This concept allows the supply of flood, mean or low flow parameters for 10790 sites in Baden-Württemberg and an evaluation of the predicted impact of climate change on the flood situation.

The extensive data basis for this regionalisation concept with numerous input parameters and varied result reporting made it necessary to select an appropriate database structure.

New software was developed to help with the calculations, notably for:

- upgrading the official areal water system register (Gewässerkundliches Flächenverzeichnis/GKFV)

- proofing tools to maintain consistency

- automatic parameter derivation with the software ESRI ${ }^{\circledR}$ ArcInfo.
\end{abstract}

The results were published in electronic form and included a stand-alone geo-information software for easy and fast retrieval of data and results.

The objective of this article is to describe the implementation of these new concepts for coupling Geographic Information System (GIS) and database needs to reach the identified requirements.

\section{Introduction}

To design water engineering structures and to evaluate the flood risk along natural watercourses, the knowledge of

Correspondence to: K. Remmler or A. S. Blatter

(hydrologie@iwg.uka.de or blatter@iwg.uka.de) flood, mean or low flow parameters is required area-wide. To allow sustainable design of flood-protection measures, including strategies for their operation, the estimation of the future development of flood flows was also included. Thus, the predicted impact of climate change has been taken into account.

To meet these demands for 10790 sites of the river network in the federal state of Baden-Württemberg, Germany $\left(36000 \mathrm{~km}^{2}\right)$, an innovative regionalisation concept was developed at the Institute of Water and River Basin Management of the Universität Karlsruhe (TH). The regionalisation concept for the flood, mean or low flow parameters bases on a multiple, linear regression approach, which is an extension of the formula of WUNDT (1953):

$$
\begin{aligned}
& \ln (Y)=C_{0}+C_{1} \times \ln \left(P_{1}\right)+C_{2} \times \ln \left(P_{2}+1\right)+C_{3} \times \ln \left(P_{3}+1\right) \\
& \quad+C_{4} \times \ln \left(P_{4}\right)+\ldots+C_{8} \times \ln \left(P_{8}\right)
\end{aligned}
$$

$Y$ is the relevant flood, mean or low flow parameter. The values $P_{1}$ to $P_{8}$ represent appropriate catchment parameters like catchment area, percentage of urban area, percentage of forest area, weighted slope, channel-segment lengths, characteristic channel-segment lengths, average annual rainfall and landscape factor.

The corresponding regression coefficients have been fitted by using the results of statistical analyses of more than 400 long-term flow series from the available gauges in the project area.

In a study called KLIWA a method has been developed to fix climate factors against different return periods and different "climate regions" of Baden-Württemberg. A detailed description of the method is published in Arbeitskreis KLIWA (2004).

By allocating a catchment to such a "climate region", it is now possible to get values for the climate factors for floods of different return periods.

The definition of the project catchments aligns to the GKFV. It involves in total 10790 sites, in detail: 6807 basic

Published by Copernicus Publications on behalf of the European Geosciences Union. 


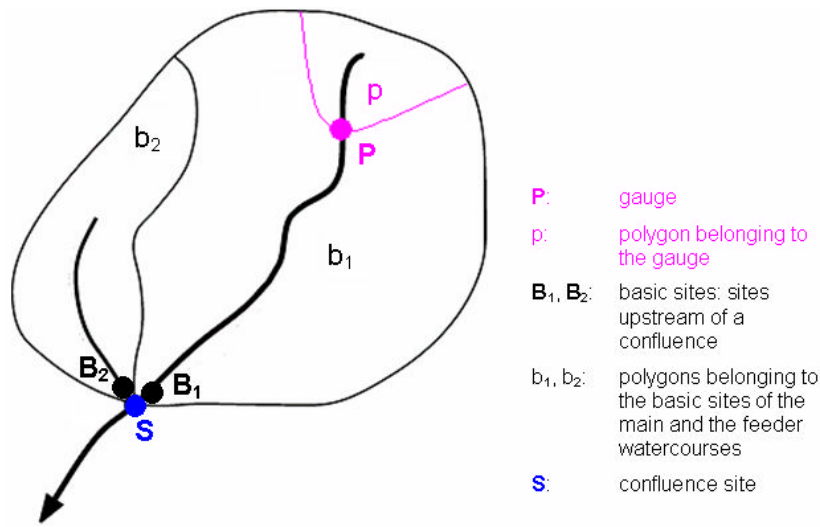

Fig. 1. Definitions of sites.

sites of the GKFV, 3380 confluence sites of those basic sites, 448 gauges and 155 special interest sites (definition of sites: see Fig. 1).

In order to i) determine and manage the regionalisation parameters $P_{1}$ to $P_{8}$ for all these sites ii) calculate the several flood, mean or low flow parameters iii) ascertain the climate factors and iv) publish the extensive result data required a tool to link the specific GIS and the database.

The objective of this article is to describe the implementation of these new concepts for coupling GIS and database needed to reach the identified requirements.

\section{Database and data preparation}

To implement the ambitious project objectives, a specific conceptual design was selected for the GIS related parts. In the course of the project, several specific developments in the processing and visualisation of GIS have been made. The extensive data basis for the regionalisation concept and the numerous result parameters made it necessary to consider a distinctive database structure.

The most interesting strategies and developments are explained and discussed in detail in the following descriptions.

\subsection{Realisation of the database}

The detailed derivation of the different flood, mean or low flow parameters and, also, the climate factors for the gauges can be found in:

- Ihringer et al. (2005) for the floods of different return periods $\left(H Q_{2}-H Q_{100}, f_{200}-f_{10000}\right)$

- Ihringer et al. (2004) for the mean flow (MQ) and low flow value (MNQ)

- Arbeitskreis KLIWA (2004) and in Arbeitskreis KLIWA (2006) the derivation of the climate factors $\left(f_{K, 2}-f_{K, 1000}\right)$ to consider the predicted climate change.
The most important geographical data for the actual investigation is represented by the GIS layer which describes the official areal water system register (GKFV). In accordance with the guidelines of the LUBW, this layer was substantially refined.

First, the geographical information of the former version of the GKFV was stored in a data type called Coverage of ESRI $^{\complement}$ ArcInfo. The official identification number (ID) of the basic sites of the former GKFV was annotated in the attribute table of the polygon layer (always the upstream adjacent polygon got the number of the basic site).

The data type Coverage provides the capability to record several layers which are linked with each other in one single dataset. Furthermore, it allows the aggregation of several polygons to a "Region" which is retained in a new layer.

The big advantage of defining Regions, is to run routines for generating a layer that describes catchments by aggregating the upstream polygons of a site automatically.

The ability to link several layers allows the modification of a boundary of a catchment on the arc layer so that all the other layers which will always include polygon layer, and may include Region layer(s) based on that arc layer, are altered simultaneously.

The upgrading process itself is described in Subsects. 2.2 and 2.3.

For deriving the percentage of urban and forest area for the catchments, a grid based on the Landsat-TM survey of the year 1993 (land use for 16 categories) has been used. This grid has been produced by the Institute for Photogrammetry and Remote Sensing (Institut für Photogrammetrie und Fernerkundung) of the Universität Karlsruhe and the RIPSPool of the institution of conservation of the federal state of Baden-Württemberg (Landesanstalt für Umweltschutz Baden-Württemberg/LfU) in 1996.

A digital elevation model (sink filled, edge length of $50 \mathrm{~m}$ ) has been applied for calculating the corresponding weighted slopes, channel-segment lengths and the characteristic channel-segment lengths. This grid was supplied by the survey administration of the federal state of BadenWürttemberg (Landesvermessungsamt Baden-Württemberg) in 1990. At the borders it has been complemented by annexing digital elevation models of Switzerland and the federal states of Hesse and Bavaria.

To derive the values for the average annual rainfall, a grid called Quartal-Rasterdaten, with a grid size of $1000 \mathrm{~m}$, has been applied. This grid was produced by the German Weather Service (DWD) in 1995 and by the RIPS-Pool of the LfU in 1996.

While using the hydrogeological units layer (Hydrogeologische Einheiten) a Coverage for the so called landscape factor was developed by Ihringer et al. (1999). This hydrogeological units layer was generated from the state office for geology, mining and resources of the federal state of Baden-Württemberg (Landesamt für Geologie, Bergbau und 
Rohstoffe Baden-Württemberg) and the RIPS-Pool of the LfU in 1996.

2.2 Interactive management tool to upgrade the official areal water system register (GKFV)

Before applying the GKFV for the purposes of the regionalisation efforts in the federal state of Baden-Württemberg, a further subdivision from former $\sim 2500$ basic sites to actual $\sim 7000$ basic sites took place. This GKFV applies a unique 13-digit number (GKFV-ID) that refers to the unique and hierarchical watercourse identification number (river ID). The GKFV-IDs must ascend in flow direction and follow some specific rules (e.g. the main stream ends with an even number, the last inflow to the next hierarchical level ends with digit 9). To assign these 13-digit numbers manually for the 4500 new subdivided catchments by following the prescribed registering rules is quite difficult, time consuming and errorprone.

To facilitate the numeration process, a special numbering support and checking tool (Fig. 2) was created using ESRI ${ }^{\complement}$ MapObjects and $\mathrm{MS}^{\complement}$ Visual Basic. The tool visualises the catchment area in a GIS window and proposes GKFV-IDs for newly created polygons. Successor and predecessor relations between sites can be set by a simple point-and-click.

In addition to generating GKFV-IDs, the tool also ascertains all confluence nodes at the watercourse and automatically generates a flow chart for the water system. Sites outside the official register (e.g. gauges or special interest sites) can be integrated into the unique numbering concept. Via an interface to the database, a further database operation allows the automatic naming of almost all 10790 regionalisation sites by river name and location.

Summary of the tool features:

- load and visualize the catchment shape

- add the river shape and show the river ID

- define multi-polygon and subdivided catchments (i.e. gauge, special interest site)

- showing and setting the successor/predecessor relations between sites

- calculate the locations of the confluence nodes between two catchments

- supported editing of the official areal water system register (GKFV)

- enumeration of all polygons by flow direction, additionally storing of successor and source catchment ID

- checking all inputs, displaying issues

- comprehensive error report

- database interface storing inputs

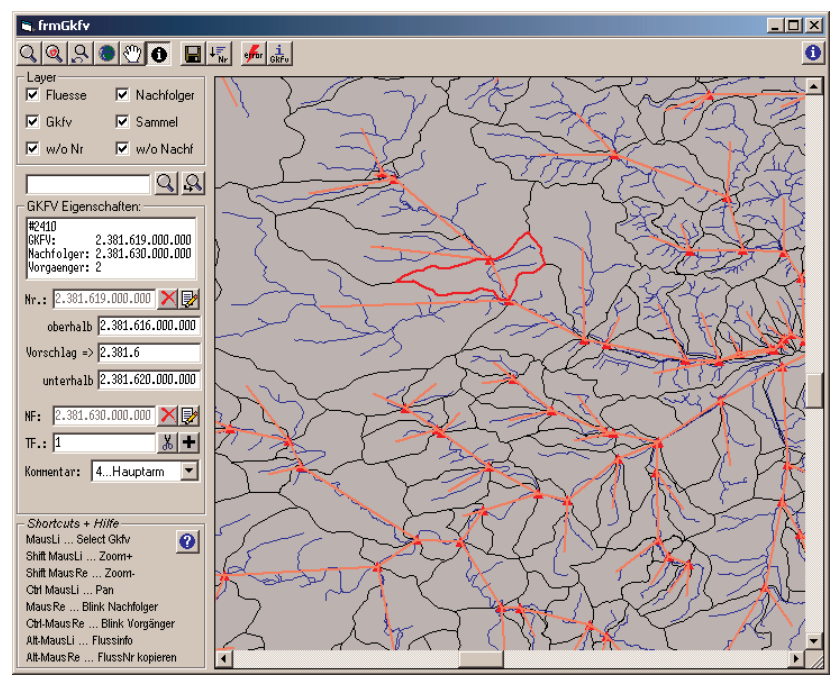

Fig. 2. Interactive tool to set stream orders, to facilitate unique IDs and to check inputs.

\subsection{Applying of the regionalisation concept}

By using Arc Macro Language (AML) of ESRI ${ }^{\circledR}$ ArcInfo, two routines could be developed:

- The first routine allows the generation of Regions according the catchments based on the previous derived flow direction and corresponding source catchment. For example for Fig. 1: catchment for the gauge $P=$ Region $P$, containing polygon $p$; catchment for basic site $B_{1}=$ Region $B_{1}$, containing polygons $p$ and $b_{1}$; catchment for basic site $B_{2}=$ Region $B_{2}$, containing polygon $b_{2}$; catchment for confluence site $S=$ Region $S$, containing polygons $p, b_{1}$ and $b_{2}$.

- The second routine enables the calculation of the catchment related parameters $P_{1}$ to $P_{8}$ for all 10790 catchments. The catchment area is derived by reading the value for the area in the attribute table of the corresponding GKFV Region. To obtain the values of all the other parameters the respective grid or coverage (e.g. land use) has to be defined by a layer that only contains the GKFV Region which represents the catchment. In some cases implemented ESRI ${ }^{\complement}$ ArcInfo commands or external Fortran routines have to be used additionally.

Finally, the flood, mean and low flow parameters were derived by applying formula (1) to linked databases using $\mathrm{MS}^{\circledR}$ Access and doing extensive validation.

The climate factors for floods of different return periods could be obtained by allocating the single catchments to "climate regions". 


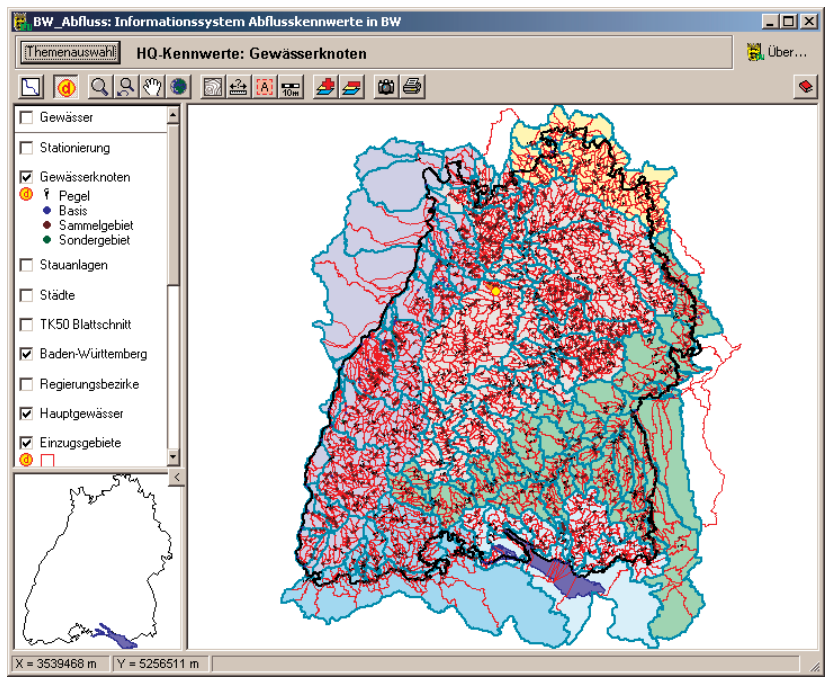

Fig. 3. BW_Afbluss: General window offering the possibility to navigate through Baden-Württemberg with the usual GIS functions, directly linked to the result window.

\section{Publication and distribution: stand-alone geographi- cal information system "BW_Abfluss"}

The result of the regionalisation covers a large amount of data (for 10790 sites, each having several parameters and values). These values include:

- floods of different return periods $\left(H Q_{2}-H Q_{100}\right)$

- factors to evaluate extreme floods $\left(f_{200}-f_{10000}\right)$

- climate factors $\left(f_{K, 2}-f_{K, 1000}\right)$ to consider predicted climate changes

- mean flow $(M Q)$ and low flow values of different return periods $\left(M N Q, N Q_{2}-N Q_{100}\right)$

- mean low flow durations $\left(N D_{2}-N D_{100}\right)$.

In addition to the above-mentioned main results, the following information is available and included in the publication:

- catchment parameters

- statistical values and graphs for the time series at the gauges

- 258 longitudinal sections along the water system with the data of different flood, mean or low flow parameters

- characteristic data of all storage basins with volume $\geq 50000 \mathrm{~m}^{3}$

- maps of land use, rainfall and the regionalisation specific landscape factor

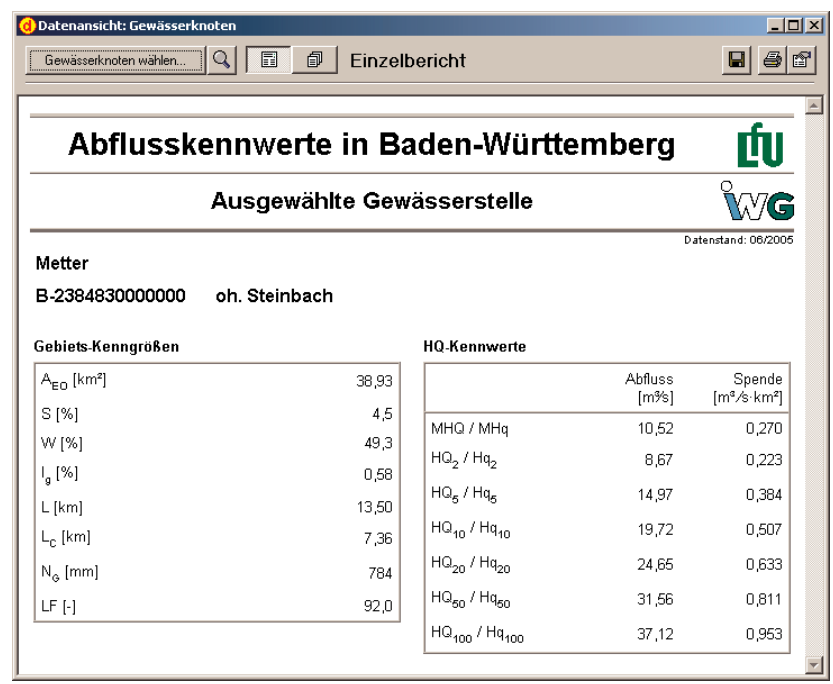

Fig. 4. BW_Abfluss: Example of a result report for a single location within Baden-Württemberg. The table on the left side summarizes the relevant characteristic values of the catchment (area, percentage of urban area, percentage of forest area, ...), the table on the right side shows the results of floods of different return periods.

- official areal water system register (GKFV), stream network and contour maps

- documentation and description of the regionalisation concept and the results.

To publish such a large amount of data and make it quick and easy to search required an electronic solution. For this specific purpose, new software was developed (Fig. 3). With this release of "BW_Abfluss: Abflusskennwerte in BadenWürttemberg" the fourth version of this software will be published (spring 2007).

While the first version was embedded into $\mathrm{ESRI}^{(}$ ArcView 3.1, now the software is a stand-alone geoinformation system with its own database which is distributed on a DVD-ROM. The system is independent from other software components, requires only a Microsoft Windows ${ }^{\circledR}$ platform and uses ESRI ${ }^{\circledR}$ MapObjects to display geographic information. The included geographic data is directly linked to the results of the regionalisation (Fig. 4) to get quick access to points of interest. Also, a searching tool is embedded to simplify queries over the large amount of sites. Additional layers, such as contour maps or even own data layers, can be loaded and displayed. All data include printing functions to save researched results.

\section{Summary and perspective}

The former releases of "BW_Abfluss: Abflusskennwerte in Baden-Württemberg" (see http://www.lubw. baden-wuerttemberg.de/servlet/is/14020/) found great 
acceptance in the water management administration of Baden-Württemberg and are used by engineering consultants, too. Furthermore the data are used as inputs for the state-wide generation of flood risk maps.

The new release provides additional values for the predicted impact of climate change and low flow values of different return periods. Moreover, the amount of represented sites has more than doubled. Hence, this release will certainly be a very helpful tool for river basin management.

The realisation of this new release demanded the handling of large amount of data and it could only be achieved by a new concept for coupling GIS and database needs. The decisive components are:

- using a data type called Coverage of ESRI ${ }^{\complement}$ ArcInfo. This data type has two big advantages: the capability to record several layers which are linked with each other in one single dataset and the possibility to aggregate several polygons to a "Region"

- a newly developed interactive management tool to upgrade the official areal water system register (GKFV) by using ESRI ${ }^{\circledR}$ MapObjects and $\mathrm{MS}^{\circledR}$ Visual Basic

- a stand-alone geo-information system with its own database which is independent from other software components.

With this method of coupling GIS and database, a very powerful tool for handling large amount of data has been developed and tested successfully under real conditions.

Acknowledgements. The authors thank the contracting authority the Landesanstalt für Umwelt, Messungen und Naturschutz Baden-Württemberg (LUBW).

Edited by: K.-E. Lindenschmidt

Reviewed by: K. Schneider and an anonymous referee

\section{References}

Arbeitskreis KLIWA (Hrsg.): Langzeitverhalten der Hochwasserabflüsse in Baden-Württemberg und Bayern, Karlsruhe, München, Offenbach: Arbeitskreis KLIWA, KIWA-Heft 2, http://www.kliwa.de/index.php?pos=ergebnisse/hefte/, 2002.

Arbeitskreis KLIWA (Hrsg.): Klimaveränderung und Konsequenzen für die Wasserwirtschaft: Fachvorträge; 2. KLIWASymposium am 03. und 04.05.2004 in Würzburg, Karlsruhe, München, Offenbach: Arbeitskreis KLIWA, KIWA-Heft 4, http: //www.kliwa.de/index.php?pos=ergebnisse/hefte/, 2004.

Arbeitskreis KLIWA (Hrsg.): Regionale Klimaszenarien für Süddeutschland, Karlsruhe, München, Offenbach: Arbeitskreis KLIWA, KIWA-Heft 9, http://www.kliwa.de/index.php?pos= ergebnisse/hefte/, 2006.

Ihringer, J., Becker, R., Brunner, R., Harlos, S., Kiefer, H., Merz, R., Neff, H.-P., Luft, G., Marusic, D., Hönig, U. und Casper, M.: Hochwasserabfluss-Wahrscheinlichkeiten in Baden-Württemberg, Landesanstalt für Umweltschutz BadenWürttemberg, Oberirdische Gewässer/Gewässerökologie, 54, 1999.

Ihringer, J., Becker, R., Blatter, A., Neff, H.-P., Preuß, P., Luft, G., Straub, H., Vormann, E., und Beerling, P.: Mittlere Abflüsse und mittlere Niedrigwasserabflüsse in Baden-Württemberg, Landesanstalt für Umweltschutz Baden-Württemberg, Oberirdische Gewässer/Gewässerökologie, 86, CD-ROM, 2004.

Ihringer, J., Becker, R., Blatter, A., Liebert, J., Preuß, P., Luft, G., und Straub, H.: Abflusskennwerte in Baden-Württemberg, T. 1: Hochwasserabflüsse, Landesanstalt für Umweltschutz Baden-Württemberg, Oberirdische Gewässer/Gewässerökologie, 94, CD-ROM, 2005.

Wundt, W.: Gewässerkunde, Berlin u.a.: Springer-Verlag OHG, 1953. 